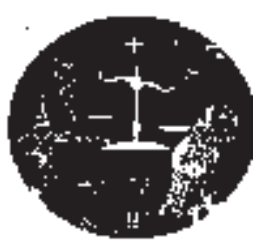

\title{
Adolescentes em conflito com a lei e VIOLÊNCIA POLICIAL: A INTERVENÇÃO PROFISSIONAL DO SERVIÇO SOCIAL
}

\section{Anderson Damião Ramos da Silva*}

Resumo: Este artigo propõe-se a investigar a trajetória da política de atendimento aos adolescentes em conflito com a lei e a apresentar as respostas profissionais do Serviço Social no Núcleo de Apoio ao Trabalho de Apuração dos Processos de Conhecimento - NAPC - ante a problemática da violência policial relatada por adolescentes atendidos pelo Núcleo. Reflete a violência como expressão da questão social, inserida na processualidade histórica que marca a sociedade capitalista. Também analisa as respostas profissionais do Serviço Social como dotadas de potencial para impor barreiras ao circuito da violência, ainda que circunscritas aos limites institucionais e às condições de trabalho advindas da relação de assalariamento a que está submetido o exercício profissional. Nesse processo, valendo-se da perspectiva teórica do materialismo histórico e utilizando como técnicas de pesquisa a análise bibliográfica e documental, o estudo se aproximou das conclusões conforme as quais a violência tem sido um componente ideológico na história da formação social brasileira e na trajetória da política de atendimento aos adolescentes em conflito com a lei. Em sua expressão de violência policial, tem simbolizado um esforço de controle (social e ideológico) das classes subalternas, constituindo-se em grave violação de direitos.

Palavras-chave: Violência. Serviço Social. Adolescentes. Socioeducação. Prática profissional.

\section{Adolescents in conflict with the law and police violence: the professional intervention from Social Work.}

Abstract: The present article proposes to investigate the trajectory of the care policy for adolescents in conflict with the law and to present the professional answers from the Social Work in Núcleo de Apoio ao Trabalho de Apuração dos Processos de Conhecimento - NAPC facing the issue of reported police violence by adolescents attended by the Service. This article identifies violence as an expression of the social issue, inserted in the historical process that marks the capitalist society. It also analyzes the professional responses from Social Work as potentially capable of imposing barriers to the cycle of violence, although restricted to institutional limits and working conditions arising from the wage ratio the professional practice is subjected to. In this process, under the theoretical perspective of historical materialism, and using as research techniques bibliographic and documentary analysis, the study approached conclusions according to which violence has been an ideological component in the history and formation of Brazilian society and in the trajectory of the care policy for adolescents in conflict with the law. In its expression of police violence, it has symbolized a social and ideological effort to control the lower classes, constituting a serious violation of rights.

Keywords: Violence. Social Work. Adolescents. Social education. Professional Practice.

\footnotetext{
* Mestrando do Programa de Pós-Graduação em Serviço Social da Universidade Federal de Santa Catarina (UFSC)
} 


\section{INTRODUÇÃO}

No âmbito da problemática que envolve adolescentes em conflito com a lei, a violência tem perpassado a história e a trajetória das políticas do atendimento socioeducativo, materializadas em atendimentos e serviços que têm se configurado, tendencialmente, em perspectivas punitivas e repressivas. Nessa trajetória, o Serviço Social tem atuado na área socioeducativa ocupando um lugar a partir do qual assistentes sociais são convocados a intervir, na condição de peritos ou analistas, lançando respostas profissionais e elementos para subsidiar decisões judiciais quanto à aplicação de medidas socioeducativas.

Motivado pelo desejo de elucidar a violência policial no âmbito do atendimento socioeducativo e na ânsia de dar visibilidade à questão, este estudo ocupou-se da investigação do significado social da violência policial e da análise das respostas profissionais do Serviço Social no Núcleo de Apoio ao Trabalho de Apuração dos Processos de Conhecimento - NAPC - ante o problema, bem como da análise da trajetória da política de atendimento à infância e adolescência no Brasil, sobretudo das legislações e serviços destinados à parcela alvo do atendimento socioeducativo.

Privilegiou-se, como caminho metodológico, a perspectiva teórica do materialismo histórico, por ser esta a mais adensada para a apreensão das mediações históricas que envolvem a violência aos adolescentes em conflito com a lei, bem como a que proporciona fecunda aproximação para com as repostas profissionais do Serviço Social no NAPC numa dimensão de totalidade. Como técnicas de pesquisa foram utilizadas a análise bibliográfica, com a investigação do conhecimento teórico produzido sobre a temática e a análise documental de dados e informações do NAPC.

\section{HISTÓRIA E TRAJETÓRIA DA POLÍTICA DE ATENDIMENTO À INFÂNCIA E ADOLESCÊNCIA NO BRASIL}

A presença da violência como componente ideológico e repressivo no atendimento à infância e à adolescência perpassou considerável parte da trajetória brasileira, superada apenas, em termos formais, com o advento do Estatuto da Criança e do Adolescente, em 1990 e a adoção da Doutrina da Proteção Integral. Compreender essa trajetória é uma premissa importante para a apreensão do significado social que a violência tem adquirido na cena contemporânea, especificamente a violência policial e seus rebatimentos e desafios para a intervenção de assistentes sociais.

Convém sintetizar, antes de adentrar na descrição da trajetória das políticas sociais de atendimento à infância e adolescência no Brasil e suas principais legislações e serviços, a concepção de política norteadora deste estudo. Behring e Boschetti (2011), analisando a contribuição da tradição marxista à compreensão das políticas sociais, as analisam "[...] como processo e resultado de relações complexas e contraditórias que se estabelecem entre Estado e sociedade civil, no âmbito dos conflitos e luta de classes que envolvem o processo de produção e reprodução do capitalismo [...]" (p. 36). Tal perspectiva exclui o entendimento das políticas sociais como ações outorgadas, neutras e isentas de associações com projetos políticos e societários. Dessa forma, compreendemos as políticas sociais a partir do processo de adensamento da questão social e da consequente luta social e política da classe trabalhadora em suas demandas imediatas e mediatas, lutas estas que dão visibilidade às expressões da questão social enquanto tais.

\section{O Brasil Colônia e republicano}

No período do Brasil Colônia não havia uma classificação etária em relação à infância e à adolescência tal qual se concebe hoje. Conforme Arantes (2009), as categorias de classificação de crianças e adolescentes no Brasil Colônia eram dadas de acordo com a filiação. Assim, havia os "[...] filhos de família, os meninos da terra, os filhos dos escravos, os órfãos, os desvalidos, os expostos [...]" (p. 192). Nesse período, a frágil assistência centralizou-se na instituição das "Rodas de Expostos", cilindros nos 
quais as crianças "enjeitadas" eram abandonadas (FALEIROS, E.; 2009). Nessas casas de acolhimento, as crianças recebiam cuidados mínimos. De acordo com a autora, o período do Brasil Colônia pode ser sintetizado como um período de negligência e de negação da vida, pois, sobrevivendo ao abandono, não restava às crianças e aos adolescentes alternativa senão o trabalho explorado.

Na época republicana, a utilização da mão de obra infantil cresceu com a incipiente industrialização. "Omissão, repressão e paternalismo [...]" (FALEIROS, V.; 2009, p. 36) são marcas das primeiras legislações referentes à infância e à adolescência nessa época. Importa destacar que essas políticas voltavam-se não para toda a parcela da sociedade, mas para o conjunto da considerada pobre, abandonada e potencialmente perigosa. De acordo com Rizzini (2009) a "[...] assistência oficial durante esse período orientava-se pela tradição de práticas caritativas, constituindo-se a partir de instituições do tipo asilar [...]" (p. 227). Posteriormente, surgiram as escolas correcionais incumbidas de corrigir, via repressão, as situações tidas como "viciosas". Para elas eram encaminhados indiscriminadamente os "menores" abandonados e os "menores" julgados criminalmente.

Como principal marco legislativo desse período, em 1927 foi promulgado o Código de Menores. Esta legislação foi criada numa perspectiva "[...] higienista de proteção do meio e do indivíduo, como a visão jurídica repressiva e moralista" (FALEIROS, V.; 2009, p. 47). A visão higienista expressava a preocupação com as condições de salubridade sem intervir nos fatores que as causavam. A visão jurídica incorporava a centralização da decisão do juiz de arbitrar sobre a criança e o adolescente, e a dimensão moralista estava relacionada à repressão à pobreza, justificada como razão para a apreensão e internamento (RIZZINI, 2009).

O Código definiu que os menores de 14 anos não podiam ser processados penalmente. Entre os $14 \mathrm{e}$ 18 anos deveriam ser julgados a partir de um processo especial. Para tanto, foi criado o Juízo Privativo de
Menores, com grande concentração de poder dos juízes, aos quais caberia a decisão sobre o internamento. O Código instituiu também que aos menores de 12 anos seria vedado o trabalho, para descontentamento, segundo Vicente Faleiros (2009), da classe industrial, que defendia a utilização massiva da mão de obra infantil.

\section{Os anOs POPUlistas de Vargas E O PERÍOdo dA DITADURA CIVIL-MILITAR}

Segundo Rizzini (2009), o período que marca o Estado Novo apresentou mudanças na configuração das políticas para a infância e a adolescência. Essas mudanças foram resultado da intervenção do governo na área da assistência com o deslocamento da questão do "menor", até então exclusiva do espaço jurídico, para a área da assistência. Permaneceu, no entanto, a ênfase no internamento, com os objetivos de "[...] preservar ou reformar os menores apreendidos" (RIZZINII, 2009, p. 242). Foram criados serviços na área da assistência e da proteção à infância a partir do "Serviço de Assistência e Proteção à Infância Abandonada e Delinquente" (Ibid. p. 243). Em 1923 é criado o Juízo de Menores do Rio de Janeiro, então capital federativa. O Juízo representa o que Rizzini (2009) denomina de "justiça assistencialista", na qual prevaleceram, no fundo, práticas discriminatórias e segregacionistas.

Posteriormente, foram criados o Serviço de Assistência ao Menor (SAM), para atendimento à causa do "menor", isto é, aos que apresentavam comportamentos classificados como de delinquência, e o Departamento Nacional da Criança (DNCr). A este cabiam ações destinadas à maternidade e à infância. Àquele competiam os serviços de internamento dos "menores" advindos do Juízo de Menores em instituições públicas e privadas (RIZZINI, 2009). Desse período, depreende-se uma tímida mudança em termos formais com a separação dos serviços à infância dos serviços destinados ao "menor".

O período inaugurado pela ditadura civil-militar, 
instaurada em 1964, iniciou-se com substituição do SAM pela Fundação Nacional do Bem-Estar do Menor, a FUNABEM. Em tempos de aprofundamento das expressões da questão social e de sua gestão, na esfera da repressão e da assistência, intensificou-se o combate aos processos de marginalização e ameaça à ordem social vigente, tão cara aos militares, sobre a qual se legitimaram a repressão e a tortura sob o viés da ideologia da segurança nacional.

A criação da FUNABEM representou um esforço de mudança do paradigma do SAM, até então centrado no internamento. Buscava agir sobre a marginalização, favorecendo a integração familiar. Competiu-lhe também elaborar a Política Nacional do Bem-Estar do Menor (PNBEM). Em termos operacionais, a FUNABEM era um órgão central ao qual cabia o repasse de recursos para as demais instituições. Posteriormente, nos estados, foram criadas as FEBEMs - Fundações Estaduais do Bem-Estar do Menor. No âmbito da PNBEM, conforme Vogel (2009), a intenção da FUNABEM era interiorizar essa política apoiando as ações de construção e implantação das instituições de atendimento nos estados, no que diz respeito à triagem e reeducação. A política efetivamente não representou avanços significativos, pois não se afastou do paradigma da internação, além de não investir na superação das causas que alimentavam a "marginalização", aproximando-se muito mais de um "[...] paradigma corretivo [...]" (FALEIROS, V., p. 72).

Outro marco legislativo deste período foi a reformulação do Código de Menores, em 1979, com a adoção da "doutrina da situação irregular". Essa perspectiva compreendia a criminalização de situações que iam desde a carência material às situações decorrentes da prática de atos infracionais. Nesse sentido, o Código operava uma moralização das condições socais responsabilizando a família ou o próprio "menor" pela sua condição social, dissociando a suposta "irregularidade" do contexto social (FALEIROS, V., 2009).

\section{A REDEMOCRATIZAÇÃO E A MUDANÇA DE PARADIGMA}

Nos anos 80, uma série de princípios e valores foi contestada pelos movimentos sociais no advento do movimento de redemocratização, alcançando-se mudanças significativas na esfera da política da infância e da adolescência. No campo dos direitos, surge - em contraposição aos paradigmas repressivos e às concepções institucionalizantes - a defesa da socioeducação, que na contemporaneidade se apresenta como diretriz na garantia de direitos das crianças e adolescentes, sobretudo dos adolescentes em situação de conflito com a lei. Para Sales (2007), a introdução da perspectiva de direitos das crianças e dos adolescentes na agenda pública brasileira ganha corpo como uma questão preponderante no fim da década de 1970, inserida no "[...] conjunto de reflexões e críticas anti-institucionais ao lado das demandas de presos políticos, prisioneiros comuns e loucos [...]" (pp. 48-49).

A promulgação do Estatuto da Criança e do Adolescente (ECA), em 1990, ao estabelecer um rol de direitos e garantias, representou um avanço na legislação de proteção das crianças e adolescentes, pois estes passaram a figurar como sujeitos de direitos e a serem contemplados, por exemplo, com o reconhecimento de sua condição de desenvolvimento e a primazia de tratamento diferenciado, em se tratando da responsabilização por atos infracionais, com a adoção das medidas socioeducativas. Essa mudança, conforme Faleiros (2009) é fruto da adoção da Doutrina da Proteção Integral.

No entanto, nos adverte Iamamoto (2010) que "[...] os direitos sociais proclamados nos estatutos legais nem sempre são passíveis de serem efetivados, visto que dependem de vontade política e de decisões governamentais [...]". Nesse sentido, o ECA não rompeu definitivamente com a trajetória ideológica de um longo período em que as demandas da infância e adolescência eram questão de polícia. Assim, a produção e reprodução da violência policial constituem um processo cuja recorrência e atualidade têm tensionado a efetivação dos direitos da infância e adolescência dispostos em lei. 


\section{A VIOLÊNCIA POLICIAL NA TRAJETÓRIA DA POLITICA DE ATENDIMENTO AOS ADOLESCENTES EM CONFLITO COM A LEI}

Considerando os teóricos que têm a violência como objeto de estudo a partir do conhecimento filosófico e sociológico, Minayo (2006, p. 17) reúne-os em três distintos grupos explicativos: o primeiro destaca a violência como uma reação dos grupos oprimidos diante das situações de "[...] crises sociais [...]". Para esse grupo, a violência significaria o enfrentamento de condições opressoras e a busca pela legitimidade de seus interesses. Seus expoentes foram Toquecville, Fanon, Sorel. O segundo grupo defende a violência como instrumento para atingir suas finalidades políticas. A análise da violência não estaria dissociada dos conflitos sociais que marcam a sociedade. Engels e Arendt se enquadram nesse grupo. Finalmente, o terceiro grupo defende a relação da violência com a cultura. A perspectiva culturalista relaciona a violência como componente cultural do homem, a qual, em diferentes estágios, assume conotações diferentes, desde a associação à agressividade natural proposta por Freud às noções da violência como modo de imposição ante outros.

No campo do pensamento filosófico ou erudito, Arendt (2009) elabora sua reflexão sobre a violência no espaço da política distinguindo-a da noção de poder. Para a filósofa não são válidas as interpretações de que a violência pode ser explicada numa perspectiva biológica e de que violência e poder são a mesma coisa. Ela defende que violência e poder são fenômenos que "[...] pertencem ao âmbito político dos negócios humanos [...]" (ARENDT, 2009, p. 103). Em termos conceituais, conforme Minayo (2006), Arendt define que a violência é instrumental na relação de busca pelo poder, mas não deve ser confundida com o próprio poder. Diz a filósofa:

o poder é de fato a essência de todo governo, e não a violência. A violência é por natureza instrumental; como todos os meios ela sempre depende de orientação e da justificação pelo fim que almeja. E aquilo que necessita de justificação por outra coisa não pode ser a essência de nada. (ARENDT, 2009, p. 68).

O poder, para Arendt (2009), tem uma finalidade em si mesma, é "[...] inerente à própria existência das comunidades políticas [...]" (p. 69), enquanto a violência precisa de justificação para sua implementação. Poder e violência convivem juntos, no entanto, um expressa o declínio da outra: o "[...] domínio pela pura violência advém de onde o poder está sendo perdido [...]" (Idem, p. 71). Em síntese, pode-se afirmar que a reflexão teórica de Hannah Arendt apreende a violência distinta, porém relacionada ao poder como um canal, um meio para alcançá-lo.

$\mathrm{Na}$ sua interpretação da violência, Engels (1979) faz uma relação entre violência e desenvolvimento econômico. Analisando o incremento e o avanço bélico ao longo da história, o autor defende que a violência acelera o processo econômico:

\footnotetext{
a violência não é um mero ato de vontade, pressupondo, pelo contrário, condições prévias bastante reais para o seu exercício, a saber: instrumentos, entre os quais, o mais perfeito esmaga o mais imperfeito. Estes instrumentos, que não brotam do solo por si sós, tiveram de ser produzidos, o que equivale a dizer que o produtor dos mais perfeitos instrumentos de violência, que são as armas, triunfa sobre o produtor dos mais imperfeitos. Daí, temos de reconhecer, em resumo, que a vitória da violência se reduz à produção de armas e que esta, por sua vez, se reduz à produção em geral, e, portanto, ao 'poderio econômico', à 'situação econômica', aos meios materiais colocados à disposição da vontade de violência (ENGELS, 1979, p. 145).
}

Nota-se que o autor associa a violência à existência de condições para seu implemento: o desenvolvimento de instrumentos, ou seja, de armas, e que, neste processo, sobressai-se a força dos que detêm os instrumentos mais perfeitos. Por seu turno, a obtenção de instrumentos bélicos mais sofisticados está condicionada ao "poderio econômico". O autor ainda 
acrescenta que a violência pode ter uma perspectiva revolucionária por ser capaz de destronar antigos regimes e suas formas políticas (ENGELS, 1979). Em contraste com essa afirmativa, Arendt (2009, p.101) elabora sua reflexão destacando, por outro lado, que a violência não pode ter uma conotação positiva, pois para ela a "[...] prática da violência, como toda ação, muda o mundo, mas a mudança mais provável é para um mundo mais violento".

Sem desconsiderar a importância dessas contribuições para o aprofundamento da reflexão sobre a violência que, a esta altura, salta-nos à compreensão como um fenômeno que "[...] não é auto-explicável e é pluricausal” (FRAGA, 2010, p. 90), considera-se aqui que as concepções que permitem uma "[...] aproximação mais fecunda com as questões [...]" (BORGIANNI, 2013, p. 416) da violência estão relacionadas à teoria crítica do materialismo histórico. Nesse sentido, pensar em violência significa pensar em estruturas de dominação, cujo fundamento encontra-se na apartação dos trabalhadores dos meios necessários à produção das riquezas socialmente produzidas. Significa pôr em conflito o capital como um sistema em cujo processo o valor significa uma "[...] relação social [...]" (HARVEY, 2013, p. 41), um meio de produção e de obtenção de mais-valia que gera estruturas desiguais, alienantes.

Como expressão da questão social, cuja gênese, conforme Iamamoto (2012, p. 156) "[...] deriva do caráter coletivo da produção contraposto à apropriação privada da própria atividade humana - o trabalho -, das condições necessárias à sua realização, assim como de seus frutos", a violência perpassa todos os espaços sociais e está associada ao modelo econômico hegemônico: o capitalista. De natureza contraditória, nesse sistema prevalece a lógica da propriedade como meio para acesso aos bens sociais e só a aquisição de mercadorias passa a ser sinônimo de felicidade (FRAGA, 2002). A apropriação de bens e mercadorias, no entanto, encontra-se monopolizada, o que gera uma violência estrutural e social, posto que está na estrutura da organização social. Contudo, conforme
Silva (2007), muitas das manifestações da violência estrutural aparecem ideologicamente naturalizadas, de modo que não são perceptíveis como tal.

Compreender a violência estrutural e social como raiz de outras expressões de violência não significa maximizar seu potencial interpretativo em detrimento de outros aspectos que a influenciam, uma vez que se trata de um "[...] fenômeno biopsicossocial [...]" (MINAYO, 1994, p. 7). Contudo, é na sociedade concreta que a violência se desenvolve e se concretiza. Para a mesma autora,

\begin{abstract}
toda violência social tem, até certo ponto, caráter revelador de estruturas de dominação (de classe, grupos, indivíduos, etnias, faixas etárias, gênero, nações), e surge como expressão de contradições entre os que buscam privilégios e os que se rebelam contra. Até a delinquência, ou principalmente a delinquência, pode ser interpretada à luz dessas relações sociais conflituosas. As desigualdades sociais, a expropriação econômica e cultural são ingredientes que importa compreender como base da criminalidade [...] (MINAYO, 1998, p. 522).
\end{abstract}

A violência estrutural revela estruturas de dominação a partir das quais diversas outras expressões de violências ganham contorno. Revela também, de acordo com Minayo (1994) mecanismos institucionais de opressão que limitam e segregam parte da sociedade do usufruto das riquezas e forjam formas naturalizadas de concepção da realidade. Reúne também, como meio de resistência, a rebeldia através do surgimento de movimentos sociais em torno de um ideal mais democrático e emancipatório.

Ainda sobre a conceituação da violência, Fraga (2002, p. 47) a compreende como uma "[...] forma de dilaceramento do ser social". Para ele, se nos primórdios a “[...] violência primária [...]” (Idem, p. 45) foi estabelecida pelos homens conforme a luta pela sobrevivência ante a ausência de outras mediações históricas, a violência em sua face atual, que ele denomina de secundária, notabiliza-se num cenário em que o homem atingiu certo nível de desenvolvimento histórico e, paradoxalmente, vive em extremas situações de desintegração. Para o citado 
autor, a violência como forma de dilaceramento do ser social expõe as mazelas de uma lógica social em que a obtenção de mercadorias - o consumismo -, passa a ser sinônimo de felicidade. A relação dos homens com seus iguais, consequentemente, assume a dimensão de uma relação mercadológica, caracterizada pelo estranhamento. $\mathrm{O}$ autor conclui ainda que é através do trabalho que o homem se reconhece. No entanto, este reconhecimento dependerá da forma como o trabalho é socialmente realizado. Assim, será apenas com a superação da forma de trabalho alienante que o homem vislumbrará um reconhecimento emancipado.

\section{A VIOLÊNCIA NA FORMAÇÃO HISTÓRICA BRASILEIRA}

No contexto histórico e social brasileiro, a violência tem acompanhado a trajetória dessas terras "tupiniquins", contrariando o mito de que somos um povo pacífico por natureza (CHAUÍ, 2000). Esse ideário de que em nossas terras convivem harmonicamente diferentes raças, credos e culturas, desempenhou, talvez, um papel ideológico de aliviar as tensões de uma sociabilidade profundamente marcada em suas origens por estruturas desiguais, de concentração de renda e de autoritarismo, presentes em tantos eventos históricos nacionais, como na ditadura militar, na contínua criminalização de movimentos sociais, assassinato de lideranças rurais e na criminalização da juventude pobre. Tais eventos, no entanto, são naturalizados ante a constatação de que "[...] somos uma formação social que desenvolve ações e imagens com força suficiente para bloquear o trabalho dos conflitos e das contradições sociais [...]" uma vez que conflitos e contradições negam a imagem de uma boa sociedade indivisa (CHAUÍ, 2000, p. 94).

Nesse sentido, a própria chegada dos colonizadores pode ser considerada em si um fato demonstrativo de violência, pois estes impuseram sua cultura aos povos indígenas de maneira agressiva e discriminatória. De acordo com Minayo (2006, p. 27), foi a violência do estupro que esteve na base do ideário criacionista do Brasil e " [...] todo o período colonial foi marcado pelo desprezo e pela crueldade contra os índios e os negros e pela exploração de sua força de trabalho e de sua cultura [...]". A imagem do mito fundador, conforme Chauí (2000), não está alicerçada nesses elementos. Pelo contrário, idealiza circunstâncias e status que encobrem e naturalizam a violência, a desigualdade e a cultura servil.

A esse perfil se acrescenta, segundo Adorno (2002), o teor patrimonialista que marcou nossos regimes políticos oligárquicos. A violência patrimonialista encontra raízes na distorção entre o público e o privado, na cultura do favor, em que este é introduzido como mediação dos serviços públicos e a partir do qual se desenvolve uma relação de dependência e de domínio, que tem no coronelismo e no clientelismo suas mais fortes expressões. São, assim, traços contributivos para a formação de uma violência social.

A violência social tem raízes nas estruturas de dominação que sustentaram os processos políticos brasileiros e que influenciaram na construção e conservação de uma sociabilidade subjugada, porém rebelde. Foi a ditadura militar, no entanto, o evento a partir do qual germinou-se o "[...] aprofundamento da cultura autoritária" (MINAYO, 2006, p. 29), quando a violência policial sob o viés do controle político era tolerada pelos governos militares (NETO, 1999). De acordo com Minayo (2006), dezoito milhões de brasileiros foram afetados pelos desdobramentos da ditadura militar, tendo direitos cerceados e limitados pela imposição dos atos institucionais. Da liberdade limitada à prática da tortura, o saldo do regime militar deixou a marca do autoritarismo mais visível a partir da violência praticada pelo próprio Estado. É, assim, um evento-chave para a compreensão da violência policial, posto que, no regime ditatorial, a violência policial praticada pelas Forças Armadas era legitimada. Conforme Neto (1999), com o fim do regime militar, de instrumento essencialmente político, a violência policial "[...] passou a ser usada como instrumento de controle da criminalidade" (p. 130).

Considerando a intensidade com que se apresenta 
no cotidiano brasileiro, julga-se oportuno tratar conceitualmente a violência policial nesse tópico, visto que ela tem íntima relação com o processo ditatorial de 1964. Neto (1999), analisando concepções teóricas da violência policial, apresenta quatro concepções conceituais e três tipos de explicações para ela. Em relação às concepções conceituais, considera a violência a partir do critério da legalidade, do critério da legitimidade, da concepção jornalística e da concepção profissional. O autor inicia a análise partindo do texto constitucional de 1988, segundo o qual o aparato policial diferencia-se dos demais cidadãos pela prerrogativa de poder utilizar a força física no cumprimento do exercício legal, ou dever legal, de suas atribuições.

O primeiro critério abordado pelo autor, classificado como critério da legalidade, é utilizado, sobretudo, no âmbito jurídico e se refere à utilização da força física pelos policiais para o cumprimento do dever legal. Haveria, assim, legalidade no uso da força física desde que associada ao exercício legal das funções da profissão. Fora desse âmbito, o uso da força física transformar-se-ia em ato de violência. Essa concepção, no entanto, desconsidera situações em que a utilização da força física é desnecessária, ou realizada para coagir. É, portanto, classificada como “[...] rígida [...]" e “[...] restrita [...]” (NETO, 1999, p. 133). A concepção ou critério da legitimidade, por seu turno, está relacionada ao que o autor chama de concepção política e sociológica da violência policial. Essa concepção abrange não só o uso da força física de maneira ilegal, mas também ilegítima, e significa que os atos de força física quando utilizados de maneira desnecessária e exagerados seriam violentos. Esses atos estariam mais passíveis de sofrerem a crítica da sociedade, conforme o sentimento de revolta que podem despertar.

A terceira concepção sobre a violência policial é denominada de concepção jornalística. Mais abrangente que as duas até aqui citadas, essa concepção incluiria além dos atos definidos como ilegais e ilegítimos, os atos irregulares, escandalosos. Em outras palavras, nessa concepção, ainda que legais e legítimos, o uso da violência policial pode ser denunciado pelos veículos de imprensa pelo clamor que cause na opinião pública. A quarta e última concepção, designada como concepção profissional, baseia-se no uso excessivo dos atos de força física, pelos policiais, de acordo com o nível de profissionalização da atuação policial. Assim, mesmo que legal, legítimo e regular, os atos de força podem ser tomados como violentos pela ausência de estratégias que dispensassem sua utilização.

Em relação às explicações para a existência da violência policial, Neto (1999) apresenta três explicações: a explicação estrutural, funcional e processual. A explicação processual ressalta as causas da violência policial como frutos de disputas e conflitos no interior da própria instituição policial; a violência seria uma instrumentalização desses conflitos. A explicação funcional destaca as funções que a violência policial adquire em contextos de mudanças sociais e analisa que a própria violência seria uma resposta a essas crises. A explicação estrutural, por sua vez, analisa as motivações da violência relacionando-as às estruturas de desigualdades sociais, econômicas e políticas.

Considerando esses três tipos de explicação para a questão da violência, cabe sinalizar que a explicação estrutural é a que mais se aproxima da perspectiva teórica adotada neste estudo. A violência policial revela, sim, estruturas de dominação a partir das quais consideráveis parcelas da sociedade têm seu cotidiano criminalizado, como a juventude negra e o conjunto de moradores das periferias dos grandes centros urbanos. Revela também mecanismos de injustiça social, de abuso de autoridade e de poder, disfarçados sob o estereótipo do controle da criminalidade.

$\mathrm{Na}$ contemporaneidade, descrever a violência requer, como premissa, entendê-la a partir dos fundamentos da sociabilidade atual, tensionada pelas expressões da questão social. Em nosso entender, tais expressões continuam tendo um fundamento comum: a contradição na relação capital e 
exploração do trabalho. Essa observação é importante para delimitar que não há uma nova questão social. Como destaca Iamamoto (2012) tornou-se comum a associação mecânica da questão social às noções de exclusão social, como se as expressões da questão social se encerrassem na exclusão social. Essa defesa esconde, no entanto, a estratégia de desmobilizar e despolitizar processos de lutas e de descaracterizar a questão social de seu fundamento: a exploração do trabalho. Conforme a mesma autora, a questão social é a mesma, assume “[...] novas roupagens [...]” (IAMAMOTO, 2012, p. 144), mas que continuam a

evidenciar a imensa fratura entre desenvolvimento de forças produtivas do trabalho social e as relações sociais que o impulsionam. Fratura esta que vem se traduzindo na banalização da vida humana, na violência escondida no fetiche do dinheiro e da mistificação do capital ao impregnar todos os espaços e esferas da vida social. Violência que tem no aparato repressivo do Estado, capturado pelas finanças e colocado a serviço da propriedade e poder dos que dominam, o seu escudo de proteção e disseminação (IAMAMOTO, 2012, p. 145).

Especificamente quanto à violência em desfavor dos jovens, aqui destacados também os adolescentes, haja vista a faixa geracional estenderse dos 15 aos 29 anos, o Mapa da Violência de 2014 revelou números profundamente preocupantes. Analisando a mortalidade juvenil, o estudo destaca que, se em décadas passadas a principal causa da mortalidade juvenil derivava de epidemias e doenças, no cenário atual esse critério cedeu lugar para as causas externas. Estas englobam as mortes por homicídio, por acidentes de trânsito e por suicídio. Os dados do estudo informam que entre os anos de 1980 a 2011 a mortalidade de jovens cresceu 32,5\%. Quanto às mortes por homicídio, esse número saltou $148,5 \%$ entre os referidos anos. Considerando o ano de 2012, houve 56.337 mortes de jovens por homicídio. Entre 1980 e 2012, os homicídios foram responsáveis por $28,8 \%$ das mortes de jovens.

\section{O NAPC E AS RESPOSTAS PROFISSIONAIS À VIOLÊNCIA POLICIAL RELATADA PELOS ADOLESCENTES}

O NAPC é um núcleo interprofissional vinculado à Terceira e à Quarta Vara da Infância e Juventude da Capital - Tribunal de Justiça do Estado de Pernambuco - TJPE. Tem sede no Centro Integrado da Criança e do Adolescente-CICA-, um complexo de instituições localizado na cidade do Recife-PE. O CICA reúne diversas instituições e órgãos que compõem o Sistema de Garantia de Direitos. A Terceira e Quarta Varas da Infância e Juventude da cidade do Recife são responsáveis por julgar processos relacionados à prática de atos infracionais circunscritos a adolescentes da cidade do Recife. Os dados que embasam esta pesquisa são oriundos de informações colhidas nos atendimentos sociais, registradas em documento interno intitulado Perfil do NAPC. Esse perfil reúne as informações dos atendimentos realizados anualmente, traçando o perfil socioeconômico e demais informações dos/as adolescentes atendidos.

Informam-se aqui os dados colhidos no ano de 2013. Nesse referido ano foram atendidos 756 adolescentes, dentre os quais 752 eram autores de ato infracional e 4 eram vítimas. $91 \%$ eram do sexo masculino e $9 \%$ do sexo feminino. A faixa etária predominante era de adolescentes entre 14 e 17 anos. Em relação à situação escolar, 51\% afirmaram estar estudando, a maioria nas séries do ensino fundamental. Quanto à renda socioeconômica, a faixa predominante corresponde a menos de um a 1,5 salário mínimo. Os/as adolescentes eram oriundos/as de todas as Regiões Político-Administrativas - RPAs da cidade do Recife. Advêm, no entanto, de bairros e comunidades periféricas. No tocante ao acompanhamento, $61 \%$ das responsáveis pelos adolescentes eram suas respectivas mães. $48 \%$ das famílias estavam inseridas em programas sociais, dentre os quais o Bolsa Família abrangia $86 \%$ delas. $57 \%$ afirmaram realizar algum tipo de atividade remunerada, boa parte na condição de informalidade. 63\% dos/as adolescentes relataram fazer uso de algum tipo de substância psicoativa, entre drogas lícitas e 
ilícitas. O quantitativo maior de substâncias relatadas foi maconha e álcool. $4 \%$ dos/as atendidos informaram sofrer algum transtorno mental. A maioria dos adolescentes estava respondendo pela primeira vez a processo por ato infracional e os principais atos destacados foram: tráfico de drogas, roubo, estupro de vulnerável e lesão corporal.

À luz de uma análise crítica que considera a realidade social de adolescentes em conflito com a lei como fruto de processos históricos e sociais, em que se sobressaem a ausência de cidadania e de direitos, é possível apreender e relacionar essas informações oriundas do NAPC à tendência histórica do tratamento e visibilidade dada ao problema no Brasil. Assim, os dados atualizam uma tendência claramente repressora e estigmatizada. A condição socioeconômica apresentada pelo/as adolescentes reflete a ausência de renda para o provimento dos mínimos básicos ou sua realização em condições-limite e a necessidade de complementação através de programas de transferência de renda. As informações alusivas à situação escolar expõem o déficit e a distorção na relação idade/série, bem como evidenciam a ausência de projetos de vida sólidos, baseados no acesso à educação e à profissionalização.

Esses dados dão conta, assim, de um rico perfil de informações sobre os usuários/as atendidos/as no Núcleo e transformam-se numa importante fonte de conhecimento sobre sua realidade social. Decorre do lugar privilegiado que ocupa o Serviço Social no contato direto com sujeitos que demandam serviços e atendimento. Cabe expressar, no entanto, que na área sociojurídica de atendimento a adolescentes em conflito com a lei não existe a mediação de um serviço social ou execução de uma determinada política de assistência, como ocorre em outros espaços ocupacionais. Conforme Borgianni (2013), nas instituições judiciárias o trabalho de assistentes sociais não corresponde a "[...] mediação dos benefícios socioassistenciais" (BORGIANNI, 2013, p. 435). Ocorre, sobretudo, a mediação de situações implicadas em processos judiciais, como no NAPC, em que o Serviço Social é chamado a opinar sobre situações concretas dispostas em conflitos, como o é o conflito com a lei.

\section{INTERVENÇÃO PROFISSIONAL E INTERFACE COM A VIOLÊNCIA: ARTICULAÇÃO ENTRE POLÍTICA DE ATENDIMENTO SOCIOEDUCATIVO E RESPOSTAS PROFISSIONAIS DO NAPC}

A intervenção profissional do Serviço Social no NAPC responde às requisições postas no cotidiano profissional e às demandas solicitadas pela instituição: $o$ atendimento a adolescentes em conflito com a lei a partir da realização de estudo social. Esse aspecto evidencia que a dimensão técnico-operativa (GUERRA, 2012) da profissão emerge como categoria a partir da qual se efetiva a relação concreta entre profissionais e usuários. Convém destacar, de partida, que as respostas profissionais que dão cor à dimensão operativa estão coadunadas às dimensões éticopolítica e teórico-metodológica, numa perspectiva de autorrelação, de autoimplicação. É a dimensão operativa, contudo, de acordo com a autora supracitada, a "[...] forma de aparecer da profissão [...]" (p. 40). Em outros termos, é na dimensão interventiva, instrumentalizada em ações, procedimentos, modos de fazer, que se materializam as respostas profissionais no âmbito do exercício profissional.

As respostas profissionais são, assim, atos, formas de atender às requisições imediatas postas no cotidiano profissional. Mas há que se considerar nesse processo as implicações decorrentes dos equívocos de equiparar essas ações a respostas meramente imediatistas, deslocando-as do componente histórico e social que caracterizam a demanda solicitada e que influem nas requisições profissionais. Significa que a dimensão interventiva não se resume à operacionalização de serviços nem sintetiza apenas a resolução de conflitos. São requisições interventivas frutos de processos históricos e sociais nos quais estão implicados e sem os quais a intervenção concreta redundaria em pragmatismo (GUERRA, 2012).

É oportuno informar, antes da descrição e análise das respostas profissionais do Serviço Social no 
NAPC, o dado relativo à violência policial relatada pelos/as adolescentes. Sobre o aspecto, as informações presentes no "Perfil NAPC 2013" dão conta que 48\% dos/as adolescentes atendidos/as informaram ter sofrido algum tipo de violência da polícia no ato de sua apreensão.

Nessas situações, as respostas profissionais procedimentos - mais frequentes relacionam-se ao esclarecimento à família atendida do remetimento automático dos autos ${ }^{1}$ do processo à Corregedoria da Polícia Militar. Realiza-se também a orientação sobre a possibilidade da família realizar denúncia no referido órgão e, por fim, há o registro no Relatório Social a partir das informações constantes nos relatos dos adolescentes. Em algumas situações, quando da existência de ameaças de morte, adota-se também o procedimento, com o consentimento do/a adolescente, de tentar inseri-lo/a em programa de proteção à vida.

No NAPC, o primeiro contato com a informação sobre a violência policial surge na recepção inicial, com a pergunta sobre a ocorrência de alguma violência sofrida pelo/a adolescente e a sua descrição. Em caso de resposta afirmativa, os entrevistados são indagados quanto ao repasse dessa informação já na audiência de apresentação, uma vez que é praxe, como informado acima, o remetimento dos autos ${ }^{1}$ do processo à Corregedoria da Polícia Militar. Ressaltese que a pergunta sobre a ocorrência da violência policial passou a integrar o formulário de cadastro inicial no ano de 2013, após reflexões sobre a recorrência dos relatos sobre a violência policial.

Ao apresentar as respostas profissionais do Serviço Social no NAPC, no atendimento aos adolescentes que relatam violência policial, importa destacar alguns aspectos implicados no problema. O primeiro diz respeito ao significado dessa violência e sua relação com a trajetória de atendimento aos adolescentes em conflito com a lei no Brasil. O segundo, não menos importante, refere-se à contextualização dessas respostas ante a perspectiva de estarem elas conformadas aos limites institucionais e às condições do exercício profissional, o que não significa, contudo, o enrijecimento de possibilidades e a negação da primazia dos princípios éticos da profissão na intervenção profissional.

O significado social da violência, entendido como o sentido e características por ela expressado, pode estar relacionado aos mecanismos de controle ideológico e de criminalidade engendrados, sobretudo, pelas instituições policiais, mas sem a elas se resumir, uma vez que fazem parte de amplo movimento de controle social encampado pelo Estado. Este, ao assumir a condição de ente legitimador do sistema capitalista, incorpora, ainda que sob o rótulo da ideologia da segurança, os princípios de apartação social e de criminalização das classes pauperizadas. A violência policial estaria, dessa forma, relacionada a mecanismos de controle social das expressões da questão social pelo Estado através das instituições policiais. Considera-se que esta realidade está inserida no histórico do tratamento repressivo e punitivo a que foram expostos adolescentes em conflito com lei ao longo da história, alvo de medidas que gravitaram em torno de perspectivas saneadoras, filantrópicas, repressivas e punitivas.

A segunda questão - a contextualização das respostas profissionais do NAPC diante do problema da violência policial relatada por adolescentes apresenta-se como intervenção fruto de conhecimentos adquiridos na formação acadêmica, plasmada pelas competências ético-política, teóricometodológica e técnico-operativa e também pela experiência cotidiana de trabalho. Estão elas, no entanto, conformadas aos limites institucionais e à condição de assalariamento dos profissionais. Isso não significa assumir uma postura fatalista em que a intervenção fica fadada aos limites fixos da instituição, uma vez que a realidade social é, sim, passível de transformação social.

Nesse sentido, as repostas profissionais do Serviço Social no NAPC têm permanecido na esfera individual, compreensível diante da própria dinâmica de realização dos atendimentos e entrevistas. Em outros termos, a intervenção profissional no problema tem sido pautada por respostas singulares. Essas, embora não signifiquem a inoperância ou inviabilização de 
direitos - muito menos o detrimento dos princípios éticos da profissão, minimizam a possibilidade de enaltecer a dimensão coletiva do problema. Enfraquecem a articulação com outros atores sociais, como movimentos sociais que lutam pela causa da infância e da juventude, pelos direitos humanos e pela não redução da maioridade penal.

Compreender a violência policial a partir desse paradigma significa entendê-la como grave prática de violação de direitos humanos, o que requisita, por seu turno, posicionamento crítico, aprofundamento teórico e intervenção coerente com os postulados éticos da profissão. Nesse sentido, é mister romper o nível aparente da questão, situando-a em sua processualidade histórica e social. Isentar-se dessa posição é incorrer no erro de analisar a violência a partir de suas fragmentações.

Para o Serviço Social impõe-se ainda o desafio de intensificar a disponibilização de informações aos usuários sobre seus direitos e as formas de acesso a eles, além de tornar cada vez mais pública a violência através da notificação nos relatórios sociais e nas instâncias de defesa dos direitos das crianças e adolescentes. Mesmo que esse avanço não represente o fim da prática da violência policial e se restrinja a um dado espaço ocupacional, representa um esforço no enfrentamento e construção de canais e barreiras à reprodução da violência policial.

\section{Notas EXPLICATIVAS}

1 Páginas do Processo Judicial em que estão transcritos os depoimentos do/a adolescente e de seus respectivos familiares ou responsáveis.

\section{REFERÊNCIAS BIBLIOGRÁFICAS}

ADORNO, S. Exclusão socioeconômica e violência urbana. Sociologias, Porto Alegre, n 8, p. 84-135, 2002.

ARANTES, E. M. de M. Rostos de criança no brasil. In: RIZZINI, I; PILOTTI, F. (Org.). A arte de governar as crianças: a história das políticas sociais, da legislação e da assistência à infância no Brasil. São Paulo: Cortez, 2009. p. 192.

ARENDT, H. Sobre a violência. Rio de Janeiro: Civilização Brasileira, 2009. p. 101.

BORGIANNI, E. Para entender o Serviço Social na área sociojurídica. Serviço Social e Sociedade, São Paulo: n. 115, p. 407-442, 2013.

BRASIL. Estatuto da Criança e do Adolescente. Lei federal $n^{\circ}$ 8069, de 13 de julho de 1990. Conselho Estadual de Defesa da Criança e do Adolescente. Recife, 2009.

ENGELS, F. Anti-Dühring: filosofia, economia política, socialismo. Rio de Janeiro: Paz e Terra, 1979. p. 145.

FALEIROS, E. T. A criança e o adolescente. Objeto sem valor no Brasil Colônia e no Império. In: RIZZINI, I; PILOTTI, F. (Org.). A arte de governar as crianças: a história das políticas sociais, da legislação e da assistência à infância no Brasil. São Paulo: Cortez, 2009. p. 203.

FALEIROS, V. de P. Infância e processo político no Brasil. In: RIZZINI, I; PILOTTI, F. (Org.). A arte de governar as crianças: a história das políticas sociais, da legislação e da assistência à infância no Brasil. São Paulo: Cortez, 2009. p. 36.

FRAGA, P. C. P. Política, isolamento e solidão: práticas sociais na produção de violência contra jovens. In: SALES, M. A.; MATOS, M. C. de; LEAL, M. Cr. (Org.). Política social, família e juventude: uma questão de direitos. São Paulo: Cortez, 2010. p. 90.

FRAGA, P. D. Violência: forma de dilaceramento do ser social. Serviço Social e Sociedade, São Paulo, n. 70, p. 44-58, 2002.

GUERRA, Y. A dimensão técnico-operativa do exercício profissional. In: SANTOS. C. M. dos; BACKX, S; GUERRA, Y. (Org). A dimensão técnico-operativa do serviço social: desafios contemporâneos. Juiz de Fora: Ed. UFJF, 2012. p. 40 .

HARVEY, D. Para entender o capital. São Paulo: Boitempo, 2013, p. 41.

IAMAMOTO, M. V. Questão Social, família e juventude: desafios do trabalho do assistente social na área sociojurídica. In: SALES, M. A.; MATOS, M. C. de; LEAL, M. C. (Org.). Política social, família e juventude: uma questão de direitos. São Paulo: Cortez, 2010.

Serviço Social em tempo de capital fetiche: capital financeiro, trabalho e questão social. São Paulo: Cortez, 2012. p. 145.

MINAYO, M. C. de S. Violência e Saúde. Rio de Janeiro: Editora Fiocruz, 2006. p. 29.

. Violência e saúde como um campo interdisciplinar e de ação coletiva. História, Ciências e Saúde - Manguinhos, Rio de Janeiro, n 3, p. 513-531, 1998.

A violência social sob a perspectiva da saúde pública. História, Ciências e Saúde - Manguinhos, Rio de Janeiro, n. 1, p. 7-18, 1994.

NETO. P. M. Violência policial no Brasil: abordagens teóricas e práticas de controle. In.: PANDOLFI... [et al]. Cidadania, Justiça e Violência. Rio de Janeiro: Ed. Fundação Getúlio Vargas, 1999.p. 133.

[SYN]THESIS, Rio de Janeiro, vol.7, nº 1, 2014, p. 41 - 53 
RIZZINI, Irma. Meninos desvalidos e menores transviados: a trajetória da assistência pública até a Era Vargas. In: RIZZINI, I; PILOTTI, F. (Org.). A arte de governar as crianças: a história das políticas sociais, da legislação e da assistência à infância no Brasil. São Paulo: Cortez, 2009. p. 227.

SALES, M. A. (In)visibilidade perversa - adolescentes infratores como metáfora da violência. São Paulo: Cortez, 2007. p. 48.

SILVA, J. F. S. da. O recrudescimento da violência nos espaços urbanos: desafios para o Serviço Social. Serviço Social e Sociedade, São Paulo, n. 89, p. 130-154, 2007.

TRIBUNAL DE JUSTIÇA DE PERNAMBUCO. Núcleo de Apoio ao Trabalho de Apuração dos Processos de Conhecimento - NAPC. Perfil NAPC 2013. Recife: TJPE, 2013.

VOGEL, A. Do estado ao estatuo. Propostas e vicissitudes da política de atendimento à infância e adolescência no Brasil contemporâneo. In: RIZZINI, I; PILOTTI, F. (Org.). A arte de governar as crianças: a história das políticas sociais, da legislação e da assistência à infância no Brasil. São Paulo: Cortez, 2009. p. 287.

WAISELFISZ, J. J. Os jovens do Brasil: mapa da violência 2014. Brasília, 2014. Disponível em: <http:// ww w.mapadaviolencia.org.br/pdf 2014 / Mapa2014_JovensBrasil.pdf>. Acesso em: 12 out. 2014. 